\title{
ANXIETY DISORDERS INDUCED HYPERTENTION: ISSUE CLINICAL CARE
}

Th. Bihari Singh ${ }^{1}$, Prakash Haldar ${ }^{2}$

\section{HOW TO CITE THIS ARTICLE:}

Th. Bihari Singh, Prakash Haldar. "Anxiety Disorders Induced Hypertension: Issues Clinical Care". Journal of Evolution of Medical and Dental Sciences 2014; Vol. 3, Issue 42, September 08; Page: 10458-10462,

DOI: $10.14260 /$ jemds/2014/3362

ABSTRACT: Anxiety is characterized most commonly as a diffuse, unpleasant, vague sense of apprehension, often accompanied by autonomic symptoms such as headache, perspiration, palpitations, tightness in the chest, mild stomach discomfort and restlessness, indicated by an inability to sit or stand still for long. Anxiety disorder is one of important cause of development of hypertension, although it is multifactorial. It increases sympathetic nervous system which causes hypertension due to alterations in baro reflex and chemo reflex pathways at both peripheral and central level. It also increases norepinephrine which acts on $\beta 1$ receptor (in brain, myocardium and kidney and increases cardiac force, rate of contraction, renin release) and $\beta 2$ receptor (in pulmonary system and blood vessels and decreases resistance of pulmonary airway and blood vessels)-leading to hypertension.

KEYWORDS: Sympathetic nervous system, Baro reflex, Chemo reflex, Norepinephrine.

INTRODUCTION: Hypertension is the leading cause of mortality worldwide. ${ }^{[1.2]}$ Though it is a multifactorial disease but anxiety plays as a risk factor. Anxiety is an independent risk factor ${ }^{[3.4]}$ that increases cardiovascular diseases (CVD) through distinct behavioral and physiological pathways.[5]

The fact that hypertension is implicated in the development and progression of CVD. Hypertension seems to be more prevalent in the subject of higher levels of anxiety.[${ }^{[6]}$ It has led to the hypothesis that hypertension may be an intermediary link between psychopathology and CVD.[7]

BLOOD PRESSURE CHANGES AND ANXIETY: AUTONOMIC NERVOUS SYSTEM: The autonomic nervous system plays a central role in maintaining cardiovascular homeostasis via pressure, volume, and chemoreceptor signals. It does this by modifying peripheral vasculature and the function of the kidneys, which affect cardiac output, vascular resistance, and fluid retention. Problems with this system, such as excess activity of the sympathetic nervous system, increase blood pressure and contribute to hypertension. ${ }^{[8,9]}$

In addition, increased activity of the sympathetic accompanied by reduced activity of the parasympathetic has been associated with many metabolic and hemodynamic abnormalities that result in increased cardiovascular morbidity and mortality.[10]

The mechanisms of increased sympathetic nervous system activity in hypertension are complex and involve alterations in baro reflex and chemo reflex pathways at both peripheral and central levels. Arterial baroreceptors are reset to a higher pressure in hypertensive patients, and this peripheral resetting reverts to normal when arterial pressure is normalized.[11]

Furthermore, there is central resetting of the aortic baro reflex in hypertensive patients, resulting in suppression of sympathetic inhibition after activation of aortic baroreceptor nerves. This baro reflex resetting seems to be mediated, at least partly, by a central action of angiotensin II.[12] 
Additional small - molecule mediators that suppress baroreceptor activity and contribute to exaggerated sympathetic drive in hypertension include reactive oxygen species and endothelia.[13]

Some studies have shown that hypertensive patients manifest greater vasoconstrictor responses to infused norepinephrine than normotensive controls.

And that hypertensive patients do not show the normal response to increased circulating norepinephrine levels which generally induces down regulation of noradrenergic receptor, and its believed that this abnormal response is genetically inherited.[14]

Exposure to stress increases sympathetic outflow, and repeated stress-induced vasoconstriction may result in vascular hypertrophy, leading to progressive increases in peripheral resistance and blood pressure. ${ }^{[15]}$ This could partly explain the greater incidence of hypertension in lower socioeconomic groups, since they must endure greater levels of stress associated with daily living.

Persons with a family history of hypertension manifest augmented vasoconstrictor and sympathetic responses to laboratory stressors, such as cold pressor testing and mental stress, that may predispose them to hypertension. Exaggerated stress responses may contribute to the increased incidence of hypertension in this group.[16]

RENIN-ANGIOTENSIN-ALDOSTERONE SYSTEM: Another system maintaining the extracellular fluid volume, peripheral resistance and that if disturbed may lead to hypertension, is the reninangiotensin-aldosterone system.

Reninis a circulating enzyme that participates in maintaining extracellular volume, and arterial vasoconstriction, Thus it contributing to regulation of the blood pressure, it performs this function through breaking down (hydrolyzes) angiotensinogen secreted from the liver into the peptide angiotensin I, Angiotensin I is further cleaved by an enzyme that is located primarily but not exclusively in the pulmonary circulation bound to endothelium, that enzyme is angiotensin converting enzyme (ACE) producing angiotensin II, the most vasoactive peptide.[17,18]

Angiotensin II is a potent constrictor of all blood vessels. It acts on the musculature of arteries and thereby raises the peripheral resistance, and so elevates blood pressure. Angiotensin II also acts on the adrenal glands too and releases Aldosterone, which stimulates the epithelial cells of the kidneys to increase re-absorption of salt and water leading to raised blood volume and raised blood pressure. So elevation of renin level in the blood will lead to hypertension.[19]

Recent studies claim that obesity is a risk factor for hypertension because of activation of the renin-angiotensin system (RAS) in adipose tissue,[20,21] and also linked renin-angiotensin system with insulin resistance, and claims that anyone can cause the other. ${ }^{[22]}$ Local production of angiotensin II in various tissues, including the blood vessels, heart, adrenals, and brain, is controlled by ACE and other enzymes, including the serine protease chymase.

The activity of local renin-angiotensin systems and alternative pathways of angiotensin II formation may make an important contribution to remodeling of resistance vessels and the development of target organ damage (i.e.left ventricular hypertrophy, congestive heart failure, atherosclerosis, stroke, end-stage renal disease, myocardial infarction, and arterial aneurysm) in hypertensive persons. 
TREATMENT APROACH: The above discussion shows that anxiety disorder is one of the leading causes of hypertension and cardiovascular diseases. Before going to treat hypertension, we should treat anxiety first if present. Treatments of anxiety disorder are mainly of two types: Cognitivebehavioral therapy and pharmacotherapy:

1. Cognitive-behavioural Therapy: sometimes it acts superior than pharmacotherapy. It removes the misinterpretation of our mind and body. The therapies are-cognitive therapy, applied relaxation, respiratory training, in vivo exposure, family therapy and insight-oriented psychotherapy.

2. Pharmacotherapy: Benzodiazepine: The drug of choice are mainly of alprazolam(1st) and clonazepam. $\left(2^{\text {nd }}\right)$ Dose of alprazolam is starting dose $0.25-0.5 \mathrm{mg}$ thrice daily and maintenance dose $0.5-2 \mathrm{mg}$ thrice daily and clonazepam starting dose $0.25-0.5 \mathrm{mg}$ twice daily and maintenance dose $0.5-2 \mathrm{mg}$ twice daily. Total duration of both drugs for $4-12 \mathrm{wks}$ then slowly tapered over 4-10wks.

SELECTIVE SEROTONIN REUPTAKE INHIBITOR: Paroxetine is drug of choice. Two types, paroxetine (dose 5 or $10 \mathrm{mg}$ daily up to $60 \mathrm{mg}$ ) and paroxetine CR (dose 12.5 or $25 \mathrm{mg}$ daily up to $62.5 \mathrm{mg}$ ). Others are sertraline, escitalopram. Combination of alprazolam and paroxetine is the best therapy.[23]

CONCLUSION: Anxiety leads to hypertension because of increased sympathetic nervous system activity and renin-angiotensin-aldosterone system, which ultimately leads to cardiovascular diseases. We must have a look to treat or rule out the anxiety disorders in every patient of hypertension and cardiovascular diseases.

\section{REFERENCES:}

1. Lim S. S, Vos T. A. D. Flaxman et al., "A comparative risk assessment of burden of disease and injury attributable to 67 risk factors and risk factor clusters in 21 regions, 1990-2010: a systematic analysis for the Global Burden of Disease study 2010," The Lancet, vol. 380, no. 9859, pp. 2224-2260, 2012.

2. Whitworth J. A. "2003 World Health Organization (WHO)/International Society of Hypertension (ISH) statement on management of hypertension," Journal of Hypertension, vol. 21, no. 11, pp. 1983-1992, 2003.

3. Kubzansky L. D. Cole S. R. I. Kawachi, P. Vokonas, and D. Sparrow, "Shared and unique contributions of anger, anxiety, and depression to coronary heart disease: a prospective study in the normative aging study," Annals of Behavioral Medicine, 31(1):p. 21-29, 2006.

4. Strik J. J. M. H, Denollet J, Lousberg R, and Honig A. "Comparing symptoms of depression and anxiety as predictors of cardiac events and increased health care consumption after myocardial infarction," Journal of the American College of Cardiology, 42(10): p. 1801-1807, 2003.

5. Rozanski, J. A. Blumenthal, K. W. Davidson, P. G. Saab, and L. Kubzansky, "The epidemiology, pathophysiology, and management of psychosocial risk factors in cardiac practice: the emerging field of behavioral cardiology," Journal of the American College of Cardiology, vol. 45, no. 5, pp. 637-651, 2005. 
6. Meng L, Chen D, Yang Y, Zheng Yand R. Hui. "Depression increases the risk of hypertension incidence: a meta-analysis of prospective cohort studies," Journal of Hypertension, vol. 30, no.5, pp. 842-851, 2012.

7. Scuteri, "Depression and cardiovascular risk: does blood pressure play a role?" Journal of Hypertension, 26(9). p. 1738-1739, 2008.

8. Takahashi H (August 2008). "[Sympathetic hyperactivity in hypertension]". Nippon Rinsho. Japanese Journal of Clinical Medicine (in Japanese) 66 (8): 1495-502.PMID 18700548.

9. Esler M (June 2000). "The sympathetic system and hypertension". American Journal of Hypertension 13 (6 Pt 2): 99S-105S. doi: 10.1016/S0895-7061(00) 00225-9.PMID 10921528.

10. Brook RD, Julius S (June 2000). "Autonomic imbalance, hypertension, and cardiovascular risk". American Journal of Hypertension 13 (6 Pt 2): 112S-122S. doi:10.1016/S0895-7061(00) 00228-4. PMID 10921530.

11. Feinleib M, Garrison RJ, Fabsitz R, et al. (October 1977). "The NHLBI twin study of cardiovascular disease risk factors: methodology and summary of results". American Journal of Epidemiology 106 (4): 284-5. PMID 562066. Retrieved 2009-06-08.

12. Lohmeier TE (June 2001). "The sympathetic nervous system and long-term blood pressure regulation". American Journal of Hypertension 14 (6 Pt 2): 147S-154S. doi: 10.1016/S08957061(01) 02082-9. PMID 11411750.

13. Li Z, Mao HZ, Abboud FM, Chapleau MW (October 1996). "Oxygen-derived free radicals contribute to baroreceptor dysfunction in atherosclerotic rabbits". Circulation Research 79 (4): 802-11. doi: 10.1161/01.res.79.4.802. PMID 8831504. Retrieved 2009-06-08.

14. Bianchetti MG, Beretta-Piccoli C, Weidmann P, Ferrier C (April 1986). "Blood pressure control in normotensive members of hypertensive families". Kidney International 29 (4): 882-8. doi: 10.1038/ki.1986.81. PMID 3520094.

15. Oparil S, Zaman MA, Calhoun DA (November 2003). "Pathogenesis of hypertension". Ann. Intern. Med. 139 (9): 761-76. doi: 10.7326 / 0003 - 4819 - 139 - 9 - 200311040 -00011. PMID 14597461.

16. Calhoun DA, Mutinga ML, Collins AS, Wyss JM, Oparil S (December 1993)."Normotensive blacks have heightened sympathetic response to cold pressor test". Hypertension 22 (6): 801-5. doi: 10.1161/01.hyp.22.6.801. PMID 8244512. Retrieved 2009-06-09.

17. Fujino T, Nakagawa N, Yuhki K, et al. (September 2004). "Decreased susceptibility to renovascular hypertension in mice lacking the prostaglandin I2 receptor IP".J. Clin. Invest. 114 (6): 805-12. doi: 10.1172/JCI21382. PMC 516260. PMID 15372104.

18. Brenner \& Rector's The Kidney, 7th ed., Saunders, 2004. pp. 2118-2119. Full Text with MD Consult subscription.

19. McConnaughey MM, McConnaughey JS, Ingenito AJ (June 1999). "Practical considerations of the pharmacology of angiotensin receptor blockers". Journal of Clinical Pharmacology 39 (6): 54759. doi:10.1177/00912709922008155.PMID 10354958. Retrieved 2009-06-09.

20. Segura J, Ruilope LM (October 2007). "Obesity, essential hypertension and renin-angiotensin system". Public Health Nutrition 10 (10A): 1151-5.

21. Hasegawa H, Komuro I (April 2009). "[The progress of the study of RAAS]". Nippon Rinsho. Japanese Journal of Clinical Medicine (in Japanese) 67 (4): 655-61.PMID 19348224. 


\section{REVIEW ARTICLE}

22. Saitoh S (April 2009). "[Insulin resistance and renin-angiotensin-aldosterone system]".Nippon Rinsho. Japanese Journal of Clinical Medicine (in Japanese) 67 (4): 729-34.PMID 19348235.

23. Kaplan and Sadock's Comprehensive Text Book. Volume-I, $9^{\text {th }}$ ed. India. Lippincott Williams and Wilkins.1839-1926.

\section{AUTHORS:}

1. Th. Bihari Singh

2. Prakash Haldar

\section{PARTICULARS OF CONTRIBUTORS:}

1. Associate Professor, Department of Psychiatry, Regional Institute of Medical Sciences, Imphal, Manipur.

2. Post Graduate Trainee, Department of Psychiatry, Regional Institute of Medical Sciences, Imphal, Manipur.

\section{NAME ADDRESS EMAIL ID OF THE CORRESPONDING AUTHOR:}

Dr. Prakash Haldar,

Department of Psychiatry,

Regional Institute of Medical Sciences, Imphal, Manipur.

Email:prakashmed03@gmail.com

Date of Submission: 21/08/2014.

Date of Peer Review: 22/08/2014.

Date of Acceptance: 30/08/2014.

Date of Publishing: 05/09/2014. 